OPEN ACCESS

Edited by: Soumitra Paul,

University of Calcutta, India

Reviewed by:

Takanori Kobayashi,

Ishikawa Prefectural University, Japan Brian M. Waters,

University of Nebraska-Lincoln, USA

${ }^{*}$ Correspondence:

Navreet K. Bhullar

bhullarn@ethz.ch

Specialty section:

This article was submitted to

Plant Nutrition,

a section of the journal

Frontiers in Plant Science

Received: 30 August 2016 Accepted: 23 January 2017 Published: 07 February 2017

Citation:

Boonyaves K, Wu T-Y, Gruissem W and Bhullar NK (2017) Enhanced Grain Iron Levels in Rice Expressing an IRON-REGULATED METAL TRANSPORTER, NICOTIANAMINE SYNTHASE, and FERRITIN Gene Cassette. Front. Plant Sci. 8:130 doi: 10.3389/fpls.2017.00130

\section{Enhanced Grain Iron Levels in Rice Expressing an IRON-REGULATED METAL TRANSPORTER, NICOTIANAMINE SYNTHASE, and FERRITIN Gene Cassette}

\author{
Kulaporn Boonyaves, Ting-Ying Wu, Wilhelm Gruissem and Navreet K. Bhullar* \\ Plant Biotechnology, Department of Biology, ETH Zurich, Zurich, Switzerland
}

Micronutrient malnutrition is widespread, especially in poor populations across the globe, and iron deficiency anemia is one of the most prevalent forms of micronutrient deficiencies. Iron deficiency anemia has severe consequences for human health, working ability, and quality of life. Several interventions including iron supplementation and food fortification have been attempted and met with varied degrees of success. Rice, which is a staple food for over half of the world's population, is an important target crop for iron biofortification. The genetic variability of iron content in the rice germplasm is very narrow, and thus, conventional breeding has not been successful in developing high iron rice varieties. Therefore, genetic engineering approaches have targeted at increasing iron uptake, translocation, and storage in the rice endosperm. We previously reported that AtIRT1, when expressed together with AtNAS1 and PVFERRITIN (PVFER) in high-iron (NFP) rice, has a synergistic effect of further increasing the iron concentration of polished rice grains. We have now engineered rice expressing AtIRT1, AtNAS1, and PVFER as a single locus gene cassette and compared the resulting lines with transgenic lines expressing AtIRT1 and PVFER gene cassettes. We also evaluated the efficacies of the MsENOD12B and native AtIRT1 promoters for the expression of AtIRT1 in rice in both types of gene cassettes, and found the native AtIRT1 promoter to be a better choice for driving the AtIRT1 expression in our biofortification strategy. All the single insertion transgenic lines have significant increases of iron concentration, both in polished and unpolished grains, but the concerted expression of AtIRT1, AtNAS1, and PVFER resulted to be a more effective strategy in achieving the highest iron increases of up to $10.46 \mu \mathrm{g} / \mathrm{g}$ dry weight. Furthermore, the transformed high iron lines grew better under iron deficiency growth conditions and also have significantly increased grain zinc concentration. Together, these rice lines have nutritionally relevant increases in polished grain iron and zinc concentration necessary to support human health.

Keywords: rice, iron biofortification, IRON-REGULATED METAL TRANSPORTER, NICOTIANAMINE SYNTHASE, FERRITIN 


\section{INTRODUCTION}

Iron deficiency is one of the most prevalent micronutrient deficiencies, affecting around two billion people globally (WHO, 2016). Children and women in the developing countries are particularly vulnerable, with 300 million children and more than 500 million women suffering from iron deficiency anemia worldwide (WHO, 2015). Consequences of iron malnutrition include poor growth and mental development, lower cognitive ability in preschool children, and increased mortality of mother and child at birth (Beard and Connor, 2003; Stoltzfus et al., 2003). In order to control and prevent iron deficiency anemia, the WHO and UNICEF recommend intervention strategies including increased iron intake via dietary diversification, supplementation, and/or fortification, overall improved nutritional status by controlling other nutritional deficiencies as well as appropriate control of infectious diseases (WHO, 2001). However, these strategies are not always successful. Iron supplementation can cause increased severity of infectious diseases in the presence of malaria (Sazawal et al., 2006), while iron fortification of food is difficult since bioavailable iron compounds often cause changes in color and flavor (Hurrell, 2002). Biofortification of staple crops is therefore a recommended choice due to its sustainability and cost effectiveness. Rice is a staple food of more than half of the world's population but contains only small amounts of micronutrients, including dietary iron. Furthermore, the micronutrient-rich layers of the grain, i.e., aleurone, bran, and husk are removed during polishing of the rice grain to increase its shelf life. Polished grains of widely grown rice varieties provide only around $2 \mu \mathrm{g} / \mathrm{g}$ of iron (Bouis et al., 2011) and therefore, rice is an important target crop for iron biofortification with recommended polished grain iron concentration of up to $15 \mu \mathrm{g} / \mathrm{g}$ dry weight (DW; Bouis et al., 2011).

Rice germplasm has a very narrow genetic variability for endosperm iron content (Gregorio et al., 2000; Glahn et al., 2002; Meng et al., 2005). Conventional breeding has therefore not been successful in increasing endosperm iron levels in popular rice varieties. Genetic engineering approaches are being used to biofortify rice, and these approaches rely on the information related to genetic network controlling iron uptake, transport, and storage. Generally, plants use reduction(strategy I) or chelation- (strategy II) based mechanisms to acquire iron from soil. Strategy I, which is utilized by most higher plant species, involves the production of FERRIC CHELATE REDUCTASE (FRO) that reduces ferric $\left(\mathrm{Fe}^{3+}\right)$ iron to ferrous $\left(\mathrm{Fe}^{2+}\right)$ iron on root surface. Soluble $\mathrm{Fe}^{2+}$ is then transported into root cells by specific transporters, e.g., IRON-REGULATED METAL TRANSPORTER 1 (IRT1). IRT1 is a member of ZINC-REGULATED TRANSPORTER/IRON REGULATED TRANSPORTER (ZRT/IRT1)-RELATED PROTEIN (ZIP) transporter family (Eng et al., 1998). In contrast, graminaceous plants utilize strategy II and release phytosiderophores (PS) that form complexes with $\mathrm{Fe}^{3+}$, which are subsequently transported into roots by members of the YELLOW STRIPE (YS) and YELLOW STRIPE-LIKE (YSL) transporter families (Curie et al., 2001; Inoue et al., 2009). All PS belonging to the mugineic acid (MA) family are synthesized from $S$-adenosyl-L-methionine by a conserved pathway of three subsequent reactions catalyzed by NICOTIANAMINE SYNTHASE (NAS), NICOTIANAMINE AMINOTRANSFERASE (NAAT), and DEOXYMUGINEIC ACID SYNTHASE (DMAS) (Kobayashi and Nishizawa, 2012). Rice plants can acquire both $\mathrm{Fe}^{2+}$ and PS-Fe ${ }^{3+}$ utilizing strategy I and II, respectively (Ishimaru et al., 2006; Cheng et al., 2007), however, strategy I is only partially utilized because of noninducible FERRIC CHELATE REDUCTASE activity in the root surface (Ishimaru et al., 2006).

Endosperm-specific expression of FERRITIN, which can store up to 4,500 iron molecules in its central cavity (Ford et al., 1984), has been the most successful approach for increasing iron storage in the rice endosperm. Rice GLOBULIN or GLUTELIN promoter-driven expression of FERRITIN could elevate iron concentration by 2- to 3.7 -fold in the polished rice grains (Goto et al., 1999; Lucca et al., 2001; Vasconcelos et al., 2003; Qu le et al., 2005; Paul et al., 2012; Oliva et al., 2014). To improve overall iron uptake and translocation within the plants, strategies focusing on increased production of iron chelators and overexpression of certain intra- and intercellular transporters were tested (Masuda et al., 2008; Suzuki et al., 2008; Lee et al., 2009b, 2012; Ishimaru et al., 2010; Johnson et al., 2011; Zhang et al., 2012; Bashir et al., 2013; Trijatmiko et al., 2016). Constitutive overexpression of NAS, which is the most widely used gene among those related to the synthesis of PS, can increase iron levels two- to fourfold in polished rice grains (Masuda et al., 2009; Johnson et al., 2011; Lee et al., 2012). The effects of other MA biosynthesis genes and several of the YSL family transporters have also been tested in rice. Expression of IRON DEFICIENCYSPECIFIC CLONE 3 (IDS3) from barley could elevate iron concentration by 1.4 -fold in polished rice grains (Masuda et al., 2008; Suzuki et al., 2008). Transformation of rice with the barley YS1 gene enhanced the iron concentration in leaves by 1.5-fold, however, no increase in grains was reported (Gomez-Galera et al., 2012). The overexpression of OsYSL15 controlled by an ACTIN promoter in rice resulted in 1.2-fold higher iron concentration in the grains (Lee et al., 2009a). Transgenic rice expressing OsYSL2 under the control of SUCROSE TRANSPORTER promoter had a fourfold iron increase in the endosperm (Ishimaru et al., 2010). Similarly, facilitating iron translocation from flag leaves to rice grains by decreasing the expression of the VACUOLAR IRON TRANSPORTER genes OsVIT1 and OsVIT2 resulted in a 1.8-fold iron increase in the endosperm (Zhang et al., 2012; Bashir et al., 2013). Among the regulatory factors of iron homeostasis, constitutive expression of the rice IRON-RELATED TRANSCRIPTION FACTOR 2 (OsIRO2), which regulates key genes involved in MA biosynthesis and iron-MA transport, resulted in a threefold increase of iron in rice grains when grown on calcareous soils (Ogo et al., 2011). It has also been reported that Zinc Finger protein 1 and 2 (OsHRZ1 and OsHRZ2), the negative regulators of rice iron deficiency responses, knockdown plants accumulate significantly higher iron in the shoots and grains, irrespective of soil iron conditions (Kobayashi et al., 2013).

Compared to the single gene strategies, the combination of genes required for effective iron transport and storage achieved higher increases in endosperm iron content. Endosperm-specific expression of FERRITIN (facilitating iron storage in endosperm) 
and PHYTASE (facilitating the release of phytic acid bound iron) together with the constitutive expression of NAS (NFP rice) resulted in a sixfold iron increase in polished grains (Wirth et al., 2009). Overexpression of barley NAS1 (HvNAS1), OsYSL2, and soybean FERRITIN from a single construct increased iron content by 3.4- and 6-fold in polished grains of a Myanmar and a Japanese rice cultivar, respectively (Masuda et al., 2012; Aung et al., 2013). Similarly, overexpression of multiple genes involved in MA production, including HvNAS1, HvNAAT, and IDS3, together with the endosperm-specific expression of FERRITIN elevated endosperm iron content by fourfold (Masuda et al., 2013). Recently, the combination of OsNAS2 and soybean FERRITIN expression resulted in iron levels reaching $15 \mu \mathrm{g} / \mathrm{g}$ in the polished rice grains (Trijatmiko et al., 2016).

The identification of rice OsIRT1 and OsIRT2 as well as their induced expression under iron deficiency conditions suggested an important function of IRT transporters in rice iron uptake (Ishimaru et al., 2006). This was further supported by the analysis of rice naat mutants that had impaired $\mathrm{Fe}^{3+}$-PS uptake but could grow normally with $\mathrm{Fe}^{2+}$ and under water-logged conditions (Cheng et al., 2007). The overexpression of OsIRT1 in rice increased iron content in shoots, roots, and mature seeds, and improved tolerance to iron deficiency growth conditions (Lee and An, 2009). Expression of heterologous IRT1 genes also improved rice growth under low iron conditions (Xiong et al., 2014) and increased iron content in mature grains (Tan et al., 2015). Recently, we found that expression of the Arabidopsis thaliana IRT1 gene (AtIRT1) under control of the Medicago sativa EARLY NODULIN 12B (MsENOD12B) promoter increased iron levels 2.1-fold in polished grains (Boonyaves et al., 2016). We also transformed the high-iron NFP rice (Wirth et al., 2009) with the MsENOD12B:AtIRT1 construct and achieved an additional 2.2-fold increase in endosperm iron content (Boonyaves et al., 2016). These results indicate that AtIRT1 is useful for iron biofortification strategies when expressed in combination with other genes encoding iron transporters, chelators, and/or storage proteins.

We engineered rice expressing an AtIRT1, AtNAS1, and PvFERRITIN gene cassette and compared the resulting lines with transgenic lines expressing AtIRT1 and PvFERRITIN gene cassettes. We also evaluated the efficacies of the MsENOD12B and native AtIRT1 promoters for the expression of AtIRT1 in rice in both types of gene cassettes. All transgenic lines show significant increases of iron content, both in the polished and unpolished grains, but highest iron levels of up to $10.46 \mu \mathrm{g} / \mathrm{g}$ DW were obtained in lines expressing the AtIRT1, AtNAS1, and PvFERRITIN gene cassette.

\section{MATERIALS AND METHODS}

\section{Construct Generation, Rice Transformation, and Plant Growth Conditions}

MsENOD12B or native AtIRT1 promoter-driven expression of AtIRT1 was combined with the endosperm-specific expression of PvFERRITIN (PvFER) under the control of rice GLOBULIN1 (GLB-1) promoter and the CaMV35S promoter-driven constitutive expression of AtNAS1. Four constructs with different combinations of these promoters and genes were generated, i.e., MIF ( $p \underline{M} s E N O D 12 B:: A t \underline{I R T 1}$, and $p O s G L B-$ $1:: P v \underline{F E R}) ; \operatorname{IIF}(p A t \underline{I} R T 1:: A t \underline{I} R T 1$, and $p O s G L B-1:: P v \underline{F E R}) ; \mathrm{MINF}$ (pMsENOD12B::AtİRT1, pCaMV35S::AtNAS1, and pOsGLB$1:: P v \underline{F E R})$; and IINF ( $p A t \underline{I}$ RT1::AtIRT1, pCaMV35S::AtNAS1, and $p O s G L B-1:: P v \underline{F E R}$ ) (Figure 1). The AtIRT1 promoter fused to the full-length AtIRT1 cDNA sequence in the pCAMBIA1300 (pIRT1) plasmid was kindly provided by Prof. Dr. Mary Lou Guerinot. The DNA fragments containing pCaMV35S::AtNAS1::tNOS and pGLB-1::PvFER::tNOS were excised from the plasmid used for generating the NFP rice (Wirth et al., 2009) and inserted into BamHI and PstI site of pIRT1 to generate IIF and IINF constructs (Figure 1). In the case of MIF and MINF constructs, the plasmid pCAMBIA1300 was cut at the BamHI and Pst I sites and the DNA fragments containing pGLB-1::PvFER::tNOS (pF), pCaMV35S::AtNAS1::tNOS, and pGLB-1::PvFER::tNOS (pNF) were appropriately inserted. The AtIRT1 gene (1,374 bp) was amplified from pIRT1 by using forward primer 5' $5^{\prime}$ AGATCTCACACAACAATCCAAAAG-3' and reverse primer $5^{\prime}$-GTCGACGAAAAAGCAGCAAAA GTT-3', followed by restriction digest of the AtIRT1 fragment with BglII and SalI before inserting it into pMSB containing the MsENOD12B promoter (Terada et al., 2001). The MsENOD12B::AtIRT1::tCaMV35S fragment was excised and then inserted into $\mathrm{pF}$ and $\mathrm{pNF}$, respectively, to generate MIF and MINF constructs (Figure 1). These DNA constructs were transferred into Oryza sativa ssp. japonica cv. Nipponbare (NB) using transformation with Agrobacterium tumefaciens strain EHA105 (Hood et al., 1993). Transformation, selection, and regeneration were based on the protocol described by Nishimura et al. (2006). Putative transformants selected by hygromycin were screened for the presence of AtIRT1, AtNAS1, and PvFER by PCR using following primers: AtIRT1fw, 5'-TGATGCTACCTTGAAGCT TAG-3' and AtIRT1rv, 5'-TCAACTGCGCCGGAAGAATG3'; AtNAS1fw, 5'-ACTCGTGTCCACGTGCTTAC-3' and AtNAS1rv, 5' $5^{\prime}$ TTGTTCATGATCGCGTGAATC-3'; and PvFERfw, 5' - GCCTCAACTGTGCCTCTTACT- $3^{\prime}$ and PvFERrv, $5^{\prime}$ - CCACAACACTACAAGTTCTTAC-3'. Southern blot hybridization using digoxigenin (DIG) labeling was conducted on BamHI digested genomic DNA isolated from the transgenic lines to select the lines with a single copy transgene insertion. AtIRT1 or AtNAS1 fragments amplified by specific primers as described above were used as probes to detect the transgenes. Single copy insertion lines were selected for each construct, i.e., 2 lines for MIF, 5 lines for IIF, 8 lines for MINF, and 13 lines for IINF (Supplementary Figure S1). Selected transgenic plants together with NB control were grown on commercial soil (Klasmann-Deilmann GmbH, Germany) in the greenhouse with $80 \%$ humidity $/ 30^{\circ} \mathrm{C} / 12 \mathrm{~h}$ light and $60 \%$ humidity $/ 22^{\circ} \mathrm{C} / 12 \mathrm{~h}$ dark. Phenotypic characteristics of the transgenic lines in $\mathrm{T}_{1}$ are presented in Supplementary Table S1. Quantification of divalent metals and transgene expression was conducted on plants in the $\mathrm{T}_{2}$ generation. 
A

MIF LB
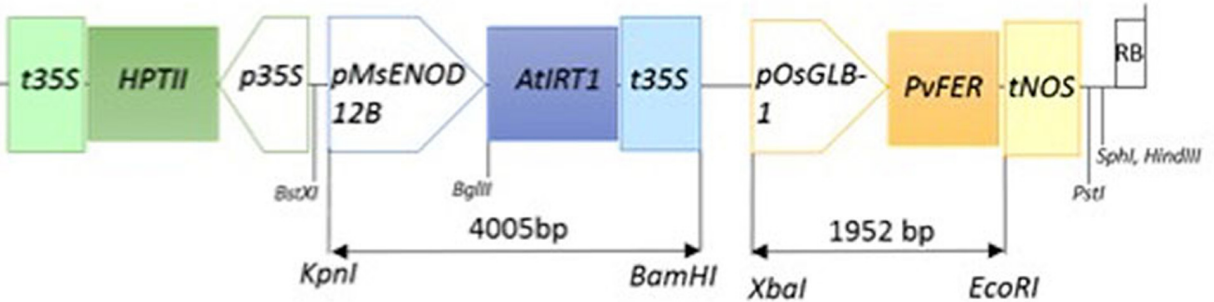

B

IIF
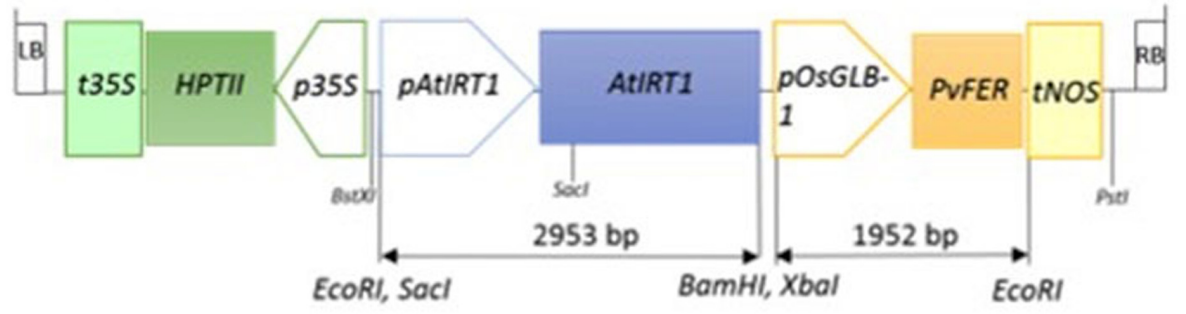

c MINF $_{\llcorner\mathrm{B}}$
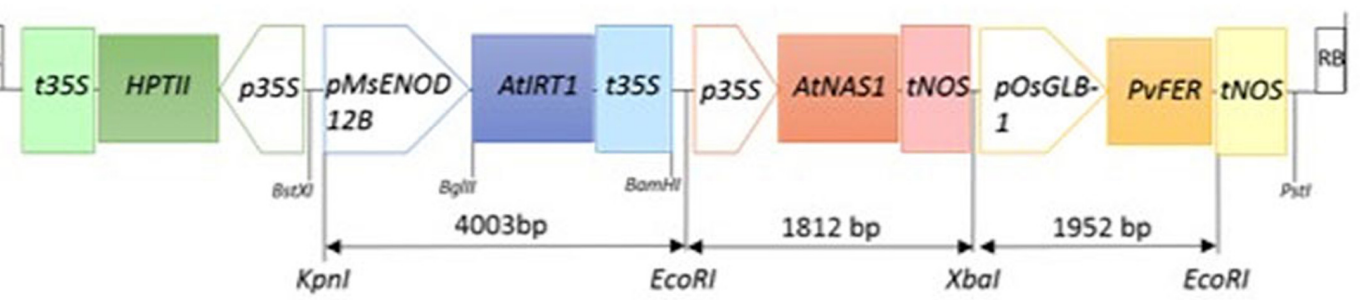

D
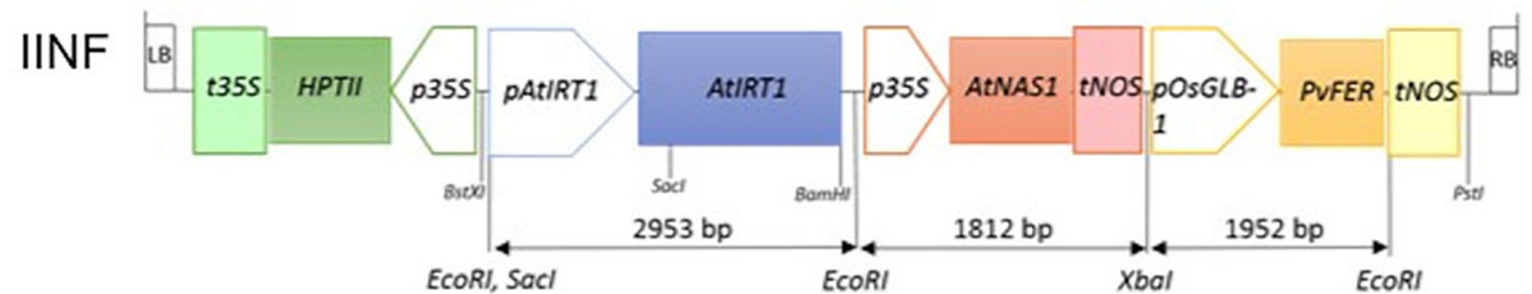

FIGURE 1 | Schematic illustration of four constructs used for transformation. MIF (A), IIF (B), MINF (C), and IINF (D) represent different transgene constructs (for details, see Materials and Methods). The length of the different DNA fragments is indicated in base pairs (bp). LB, T-DNA left border; RB, T-DNA right border; t35S, cauliflower mosaic virus (CaMV) 35S terminator; HPTII, HYGROMYCIN PHOSPHOTRANSFERASE gene; p35S, CaMV 35S promoter; pMsENOD12B, Medicago sativa EARLY NODULIN 12B promoter; AtIRT1, Arabidopsis IRON REGULATED METAL TRANSPORTER 1 gene; pAtIRT1, AtIRT1 promoter; AtNAS1, Arabidopsis NICOTIANAMINE SYNTHASE 1 gene; tNOS, NOPALINE SYNTHASE terminator; pOsGLB-1, rice GLOBULIN-1 promoter; PVFER, Phaseolus vulgaris FERRITIN gene; BstXI, Kpnl, EcoRI, Sacl, Bg/ll, BamHI, Xbal, and Pstl: restriction enzyme sites.

\section{Metal Ion Measurements}

Grain samples were de-husked to obtain unpolished brown grains. The de-husked grains were milled with a grain polisher (Kett grain polisher "Pearlest," Kett Electric Laboratory, Tokyo, Japan) for $1 \mathrm{~min}$ to obtain polished grains. To measure iron concentration in shoots and roots, 1-week-old seedlings were grown on hydroponic solution (Kobayashi et al., 2005) containing different iron supplies $(5 \mu \mathrm{M} \mathrm{Fe-EDTA} \mathrm{for} \mathrm{iron-}$ deficient and $100 \mu \mathrm{M}$ Fe-EDTA for iron-sufficient conditions) for 1 week. Shoot and root samples were dried at $60^{\circ} \mathrm{C}$ for 5 days. Ground samples were boiled in $15 \mathrm{ml}$ of $65 \% \mathrm{v} / \mathrm{v} \mathrm{HNO}_{3}$ solution at $120^{\circ} \mathrm{C}$ for $90 \mathrm{~min}$. Subsequently, $3 \mathrm{ml}$ of $30 \% \mathrm{v} / \mathrm{v} \mathrm{H}_{2} \mathrm{O}_{2}$ were added and boiled at $120^{\circ} \mathrm{C}$ for $90 \mathrm{~min}$. Metal concentrations were determined using inductively coupled plasma-optical emission spectroscopy (ICP-OES) (Varian Vista-MPX CCD Simultaneous ICP-OES). The wavelength used for iron, zinc, manganese, and copper were $238.204,213.857,257.610$, and $324.754 \mathrm{~nm}$, respectively. The National Institute of Standards and Technology (NIST) rice flour standard 1568a (NIST, USA) ${ }^{1}$ was treated and analyzed in the same manner and used as quality control for every

\footnotetext{
${ }^{1}$ https://www-s.nist.gov/srmors/view_detail.cfm?srm=1568a
} 
measurement. Data were analyzed using Student's $t$-test, and the statistically significant differences among the tested lines were determined based on $P=0.05$ and $P=0.01$.

\section{Pearl's Prussian Blue Staining}

Rice seeds were stained as described (Prom-u-Thai et al., 2003). Unpolished grains were cut longitudinally with a ceramic knife (Cerastar ${ }^{\circledR}$, Germany) in a Petri dish. The cut grains were submerged in freshly prepared Pearls' Prussian blue solution (2\% hydrochloric acid and $2 \%$ potassium ferrocyanide) for $10 \mathrm{~min}$ and then washed gently in distilled water for $2 \mathrm{~min}$. Stained seeds were examined by a stereomicroscope (Keyence, VHX-1000D).

\section{Quantitative Real-Time PCR}

To determine transgene AtIRT1 expression, rice $\mathrm{T}_{2}$ seedlings were germinated on hydroponic solution (Kobayashi et al., 2005) in a Petri dish sealed with a tape, particularly to improve collection of root hairs. Total RNA was extracted from shoots and roots of 5-day-old seedlings using Trizol ${ }^{\circledR}$ reagent (Invitrogen, USA). To obtain total endosperm RNA, endosperm was excised from rice grains at 3 weeks after anthesis. Extraction buffer containing $0.15 \mathrm{M} \mathrm{NaCl}$ and $1 \%$ sarkosyl was added into the ground endosperm samples followed by purification with guanidine hydrochloride buffer (Sharma et al., 2003). The RNA was treated with DNase I (Thermo Fisher Scientific Inc., USA) to remove DNA contamination. First-strand cDNA was synthesized using the RevertAid ${ }^{\mathrm{TM}}$ first strand cDNA synthesis kit (Thermo Fisher Scientific Inc., USA). Quantitative real-time PCR (qRTPCR) was performed using the 7500 FAST Real Time PCR system (Applied Biosystem, Inc., USA). Total reaction volume of $20 \mu \mathrm{l}$ included $4 \mu \mathrm{l} \mathrm{cDNA}, 0.5 \mu \mathrm{l}$ forward primer, $0.5 \mu \mathrm{l}$ reverse primer, $10 \mu \mathrm{l} \mathrm{SYBR}{ }^{\circledR}$ Green PCR Master Mix (Applied Biosystems Ltd., USA), and $5 \mu \mathrm{l} \mathrm{H}_{2} \mathrm{O}$. The Ct value was calculated using the 7500 Fast System Software (Applied Biosystems, Inc., USA). Relative quantification of the transgene by $2^{-\Delta \mathrm{Ct}}$ analysis was performed using a primer set as provided in Supplementary Table S2. The data were normalized in reference to the endogenous expression of Os01g0147200 (IWS1, C-terminal family protein), which was selected using Genevestigator ${ }^{\circledR 2}$ based on its stable expression.

\section{RESULTS}

\section{Concerted Expression of AtIRT1, AtNAS1, and PvFERRITIN Increases Iron Concentration in Polished Rice Grains}

The expression of the transgenes was analyzed in several independent single copy insertion lines for each construct (Figure 2; see also Figure 1 and Supplementary Figure S1). Shoots and roots generally showed the expected expression of AtIRT1 and AtNAS1 but not PvFERRITIN, consistent with the choice of promoters, although the activity of the promoters was variable among different independent lines (Figure 2). However, in most lines AtIRT1 was more strongly expressed in roots, especially

${ }^{2}$ https://genevestigator.com/gv/
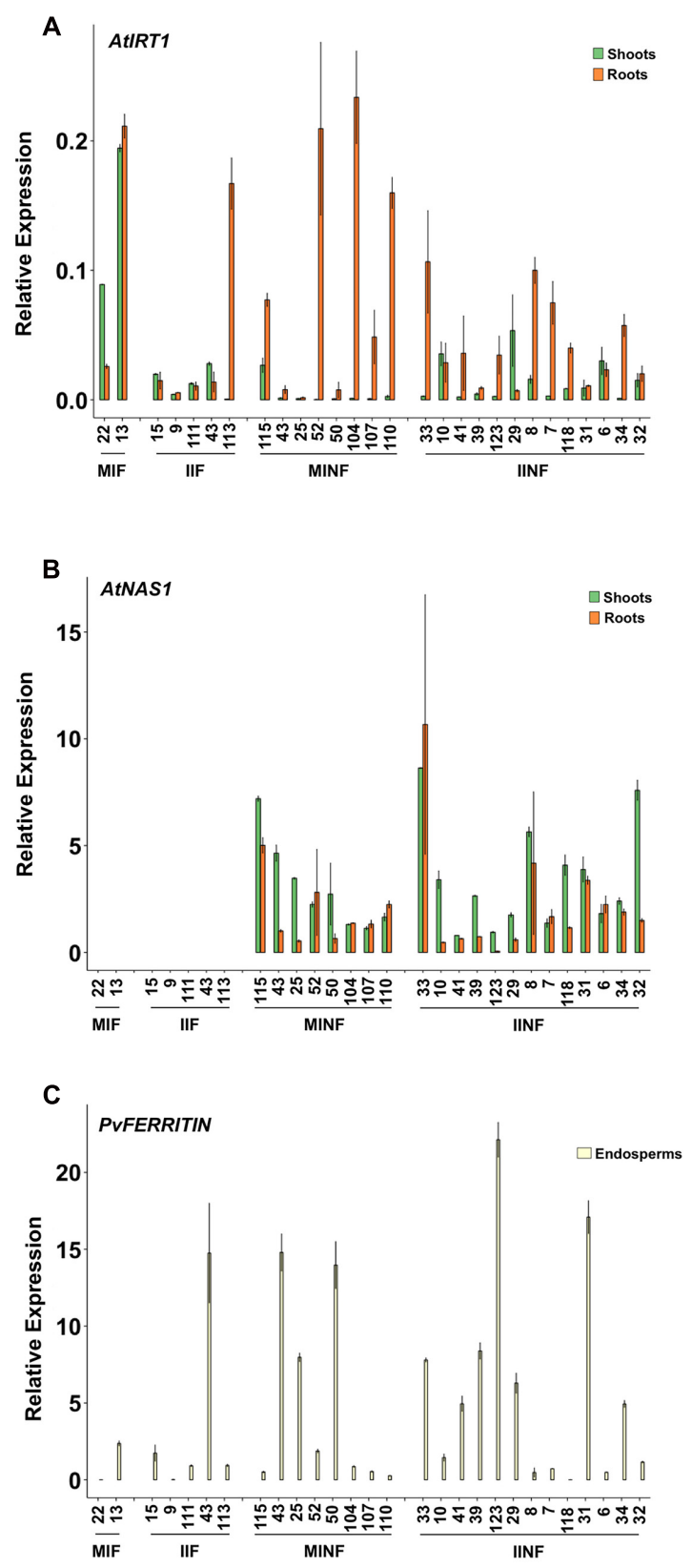

FIGURE 2 | Expression analysis of AtIRT1, AtNAS1, and PVFERRITIN in transgenic lines. Relative expression of AtIRT1 (A) and AtNAS1 (B) in roots and shoots of $\mathrm{T}_{2}$ seedlings, and the relative expression of PVFERRITIN (C) in the endosperm of $T_{3}$ grains was analyzed. Values are the average of three biological replicates ( \pm standard deviation). MIF, plants with the pMsENOD12B::AtIRT1::t35S and pGLB-1::PVFER::tNOS transgenes; IIF, plants with the pAtIRT1::AtIRT1 and pGLB-1::PVEER::tNOS transgenes; MINF, plants with the pMsENOD12B::AtIRT1::t35S, pCaMV35S::AtNAS1::tNOS and pGLB-1::PVFER::tNOS transgenes; IINF, plants with the pAtIRT1::AtIRT1, pCaMV35S::AtNAS1::tNOS and pGLB-1::PVFER::tNOS transgenes.

in the MINF and IINF lines. Both MsENOD12B and AtIRT1 promoters are active in root hair and epidermal cells (Terada et al., 2001; Cailliatte et al., 2010), and it cannot be excluded that the AtIRT1 expression specificities in Figure 2 were biased 


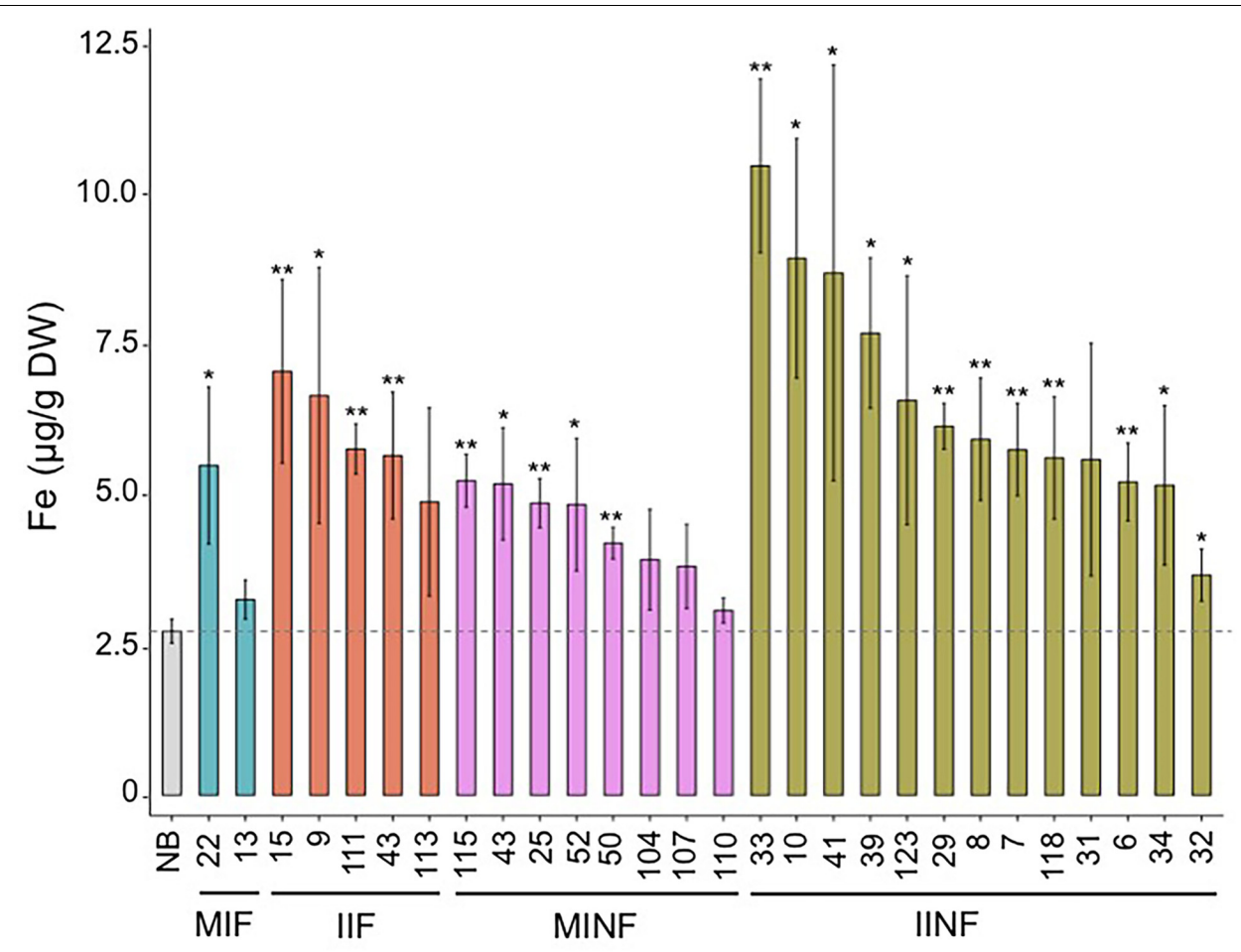

FIGURE 3 | Iron concentration in the polished $\mathbf{T}_{2}$ grains of lines with different promoter-transgene combinations. Values are the average of three biological replicates ( \pm standard deviation). Asterisks above the bars indicate significantly higher values calculated using Student's $t$-test in comparison to the Nipponbare (NB) control ( $\left.{ }^{*} P<0.05,{ }^{*} P<0.01\right)$, respectively. NB, rice cultivar Nipponbare; for other abbreviations, see legend of Figure 2.

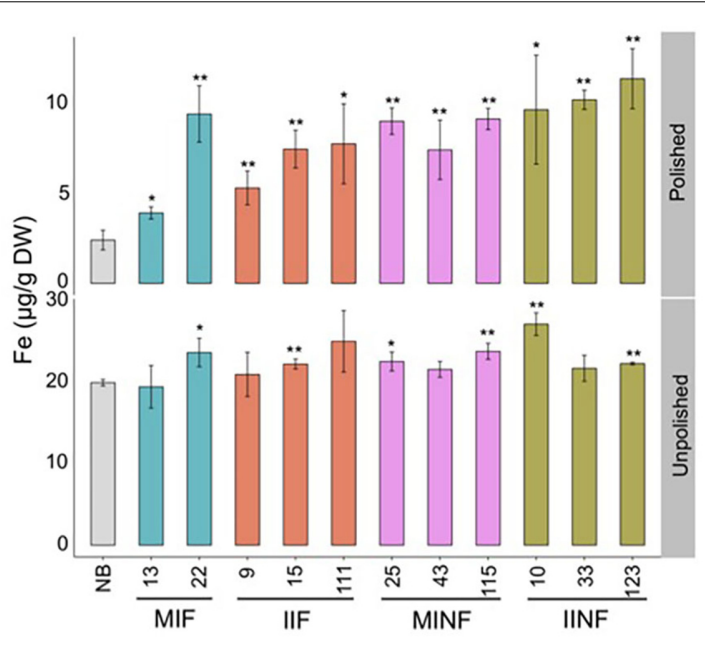

FIGURE 4 | Iron distribution in the $\mathrm{T}_{3}$ grains of selected transgenic lines. Iron concentration in the $\mathrm{T}_{3}$ grains of transgenic plants and Nipponbare (NB) control. Values are the average of three biological replicates $( \pm$ standard deviation). Asterisks above the bars indicate significantly higher values calculated using Student's $t$-test in comparison to the NB control $\left({ }^{*} P<0.05\right.$, $\left.{ }^{* *} P<0.01\right)$, respectively. For abbreviations, see legend of Figure 2.

by proportional differences in the amount of root hair cells in the collected root samples. In some lines AtIRT1 was expressed more strongly under the control of the MsENOD12B promoter, but in general both $M s E N O D 12 B$ and AtIRT1 promoters showed variable activities, most likely resulting from position effects on the transgene constructs. PvFERRITIN was expressed only in the rice endosperm, consistent with the endosperm specificity of the OsGLB1 promoter (Figure 2).

Most of the transgenic MIF, IIF, MINF, and IINF lines (see Figure 1) had increased iron concentrations of more than $5.0 \mu \mathrm{g} \mathrm{g}^{-1} \mathrm{DW}$ in polished $\mathrm{T}_{2}$ grains as compared to $2.73 \mu \mathrm{g} / \mathrm{g}$ DW iron in the NB control (Figure 3). The highest iron concentration in MIF lines was $5.48 \mu \mathrm{g} / \mathrm{g} \mathrm{DW}$ (MIF 22), in IIF lines $7.05 \mu \mathrm{g} / \mathrm{g}$ DW (IIF 15), and in MINF lines $5.23 \mu \mathrm{g} / \mathrm{g}$ DW (MINF 115). Several of the IINF lines had $>7.0 \mu \mathrm{g} / \mathrm{g}$ DW iron in polished grains, which is significantly above the median of the MINF, MIF, and IIF lines. Highest iron concentration was observed in the polished grains of IINF $33(10.46 \mu \mathrm{g} / \mathrm{g} \mathrm{DW})$, which is 3.8 -fold higher than the NB control. The IINF and IIF lines generally have higher endosperm iron concentration than MINF and MIF lines, suggesting that the AtIRT1 promoter is more effective than the MsENOD12B promoter in our biofortification strategy. However, a robust conclusion about promoter efficacy requires the analysis of many more transgenic lines than could be accomplished in our study. The endosperm iron concentration in the transgenic lines does not always correlate with the expression levels of AtIRT1, neither under the control of the MsENOD12B nor AtIRT1 promoter (Figure 2), suggesting that other processes may influence iron accumulation in independent transgenic 


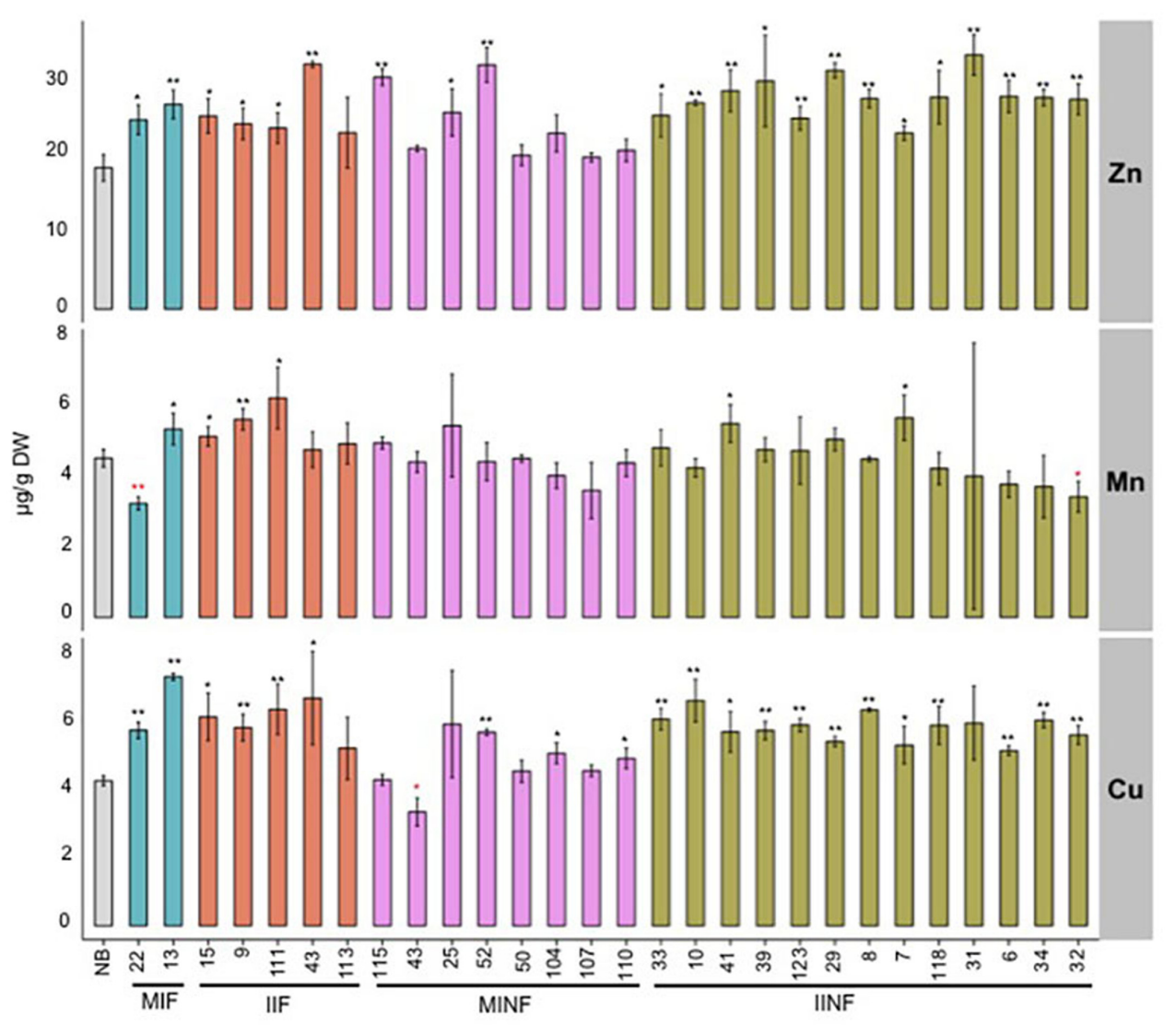

FIGURE 5 | Zinc, manganese, and copper concentrations in the polished $\mathbf{T}_{\mathbf{2}}$ grains of lines expressing different promoter-transgene combinations. Values are the average of three biological replicates ( \pm standard deviation). Black and red asterisks above the bars indicate significantly higher or lower values calculated using Student's $t$-test in comparison to the NB control $(* P<0.05, * * P<0.01)$, respectively. For abbreviations, see legend of Figure 2.

lines as well. But the data in Figure 3 suggests that the concerted expression of AtIRT1, AtNAS1, and PvFER is a more effective strategy to increase endosperm iron levels as compared to the expression of AtIRT1 and PvFER, irrespective of the promoters.

Analysis of selected lines confirmed that the T2 grain iron increases were maintained in both polished and unpolished T3 grains (Figure 4). Polished grains of MIF, IIF, MINF, and IINF had up to 3.9-, 3.2-, 3.8-, and 4.7-fold increased iron concentration as compared to the NB control, respectively. IINF T3 grains had the highest iron accumulation in the endosperm with more than $10 \mu \mathrm{g} / \mathrm{g}$ DW in line 123. The transgenic lines also had increased iron accumulation in the unpolished T3 grains, although the difference to the NB control was significantly lower, further substantiating the iron increase in the endosperm (Figure 4). Prussian blue staining of transgenic grains confirmed the increased iron localization in the endosperm (Supplementary Figure S2). Iron localization in the $\mathrm{NB}$ control was restricted to the radical and scutella in the embryo and to the aleurone cell layer, while in the transgenic grains iron also accumulated in the endosperm.

\section{The Accumulation of Other Divalent Metals is Increased in Polished Transgenic Grains}

In addition to iron, other metal ions including zinc, manganese, and copper were also quantified in the T2 transgenic grains. Zinc concentration was significantly increased in polished grains of most transgenic lines compared to the NB control (Figure 5). The highest zinc concentration of $33.17 \mu \mathrm{g} / \mathrm{g}$ DW was found in the polished grains of IINF31, which is 1.8 -fold higher than the NB control. Six of the 28 transgenic lines had higher manganese concentration with up to $6.22 \mu \mathrm{g} / \mathrm{g}$ DW in IIF111. Two of the 28 transgenic lines had slightly reduced manganese levels, but this did not correlate with higher iron levels. Most transgenic lines also had increased copper levels in polished grains, ranging between 5.00 and $7.43 \mu \mathrm{g} / \mathrm{g}$ DW, as compared to $4.33 \mu \mathrm{g} / \mathrm{g}$ DW in NB polished grains.

\section{Iron Homeostasis in Shoots and Roots of the Transgenic Rice Lines Grown in Iron Sufficient and Deficient Conditions}

Iron accumulation in the shoots and roots of the tested transgenic lines containing increased grain iron concentration 
was variable but in most lines less than 50\% different from the NB control under iron sufficient and deficient conditions (Figure 6). Roots of the NB control had $2112.17 \mu \mathrm{g} / \mathrm{g} \mathrm{DW}$ iron when sufficient iron was available, but only $658.16 \mu \mathrm{g} / \mathrm{g}$ DW iron under iron deficiency conditions. Under iron sufficient conditions, line IIF15 had a 2.1-fold increased iron concentration in the shoot while most other lines had shoot iron levels similar to the NB control (Figure 6A). Root iron levels under deficiency conditions were similar to NB roots in most transgenic lines except lines MIF13, MIF22, IIF15, MINF115, and IINF33, which showed variable increases in the root iron concentration (Figure 6B). In contrast, most transgenic lines accumulated more iron in the shoots than the $\mathrm{NB}$ control under iron deficiency (Figure 6B). Two of the transgenic lines, MINF115 and IINF10, were exposed to iron deficiency for 2 weeks for phenotypic observation, and these lines exhibited better growth and reduced chlorosis in comparison to the control (Figures 6C,D). Phenotypic assessment of the transgenic lines showed that most lines were similar to the $\mathrm{NB}$ control with respect to the plant height, tiller numbers, days to flowering, panicle numbers and 1,000 grain weight (Supplementary Table S1).

\section{DISCUSSION}

We have demonstrated that tissue-specific expression of IRT1 in combination with NAS and FERRITIN from a single gene cassette can be used to increase iron levels, and lines with iron concentrations of up to $10.46 \mu \mathrm{g} / \mathrm{g} \mathrm{DW}$ in the polished rice grains are reported. Conventional breeding and agronomic micronutrient fortification have shown promises for improving zinc but not iron concentration in cereal grains (Cakmak, 2008; Ahmad et al., 2012; Phattarakul et al., 2012). Among the genetic engineering strategies, those combining two or more genes were relatively more successful in increasing rice endosperm iron concentrations (Wirth et al., 2009; Masuda et al., 2012, 2013; Aung et al., 2013). For example, we previously reported that endosperm-specific expression of FERRITIN and PHYTASE together with the constitutive expression of NAS (NFP rice) resulted in a sixfold increased rice endosperm iron concentration (Wirth et al., 2009). A recent study reported $15 \mu \mathrm{g} / \mathrm{g}$ DW iron in polished grains of a field-grown transgenic line expressing NAS and FERRITIN (Trijatmiko et al., 2016), but the reported lines have two transgene cassette copies integrated as an inverted repeat. There is currently little evidence that the duplicated and inverted transgene locus in these lines can be stably maintained over generations. It has been repeatedly reported by different laboratories that two or more insertions of a transgene often result in epigenetic transgene silencing in later plant generations (e.g., Kumpatla and Hall, 1998; Li et al., 2002; Tang et al., 2006; Rajeevkumar et al., 2015). Therefore, it is likely that transgene cassette copies integrated as an inverted repeat may not inherit the iron and zinc trait over multiple generations. This makes the suitability of such an inverted transgene cassette repeat line questionable for breeding programs. Therefore, development of iron-biofortified rice lines should be continued using best single
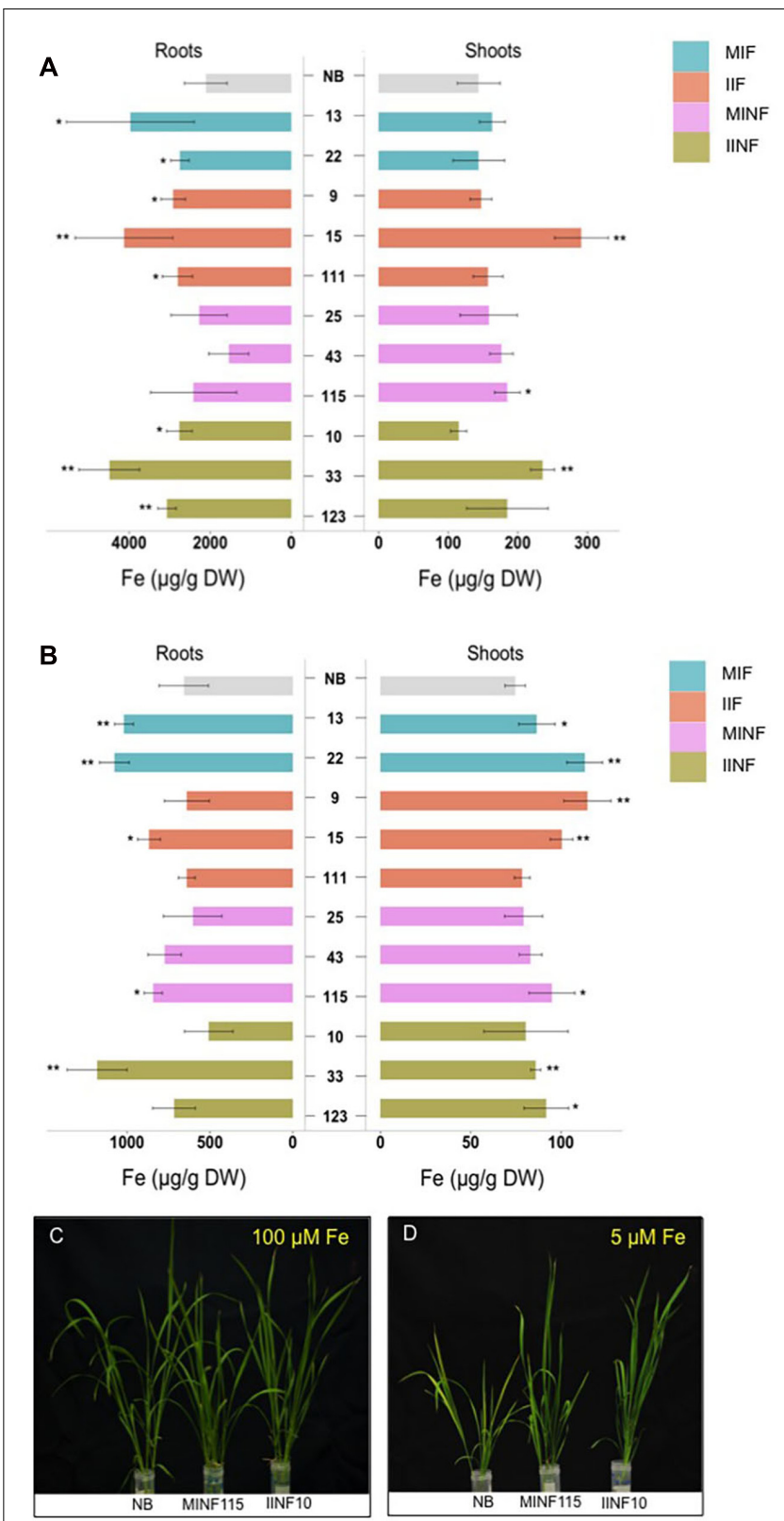

FIGURE 6 | Iron concentrations in shoots and roots of transgenic lines grown in different iron conditions. Iron concentration in roots and shoots of seedlings that were grown in sufficient $(\mathbf{A})$ and deficient $\mathbf{( B )}$ iron concentration conditions for 1 week. Values are the average of four biological replicates ( \pm standard deviation). Note the differences in scale of the $x$-axis $(\mathbf{A}, \mathbf{B})$ indicating the measured iron concentration. Asterisks above the bars indicate significantly higher values calculated using Student's $t$-test in comparison to the NB control $\left({ }^{*} P<0.05,{ }^{* *} P<0.01\right)$, respectively. Phenotypic appearance of transgenic lines and NB control after the seedlings were grown in sufficient (C) and deficient (D) iron concentration conditions for 2 weeks. For abbreviations, see legend of Figure 2.

copy transgene cassette insertion lines with Fe accumulation that is stably inherited and that can be bred efficiently and robustly into widely grown rice cultivars. Here we report single copy cassette insertion rice lines with endosperm Fe concentrations 
reaching $10.46 \mu \mathrm{g} / \mathrm{g}$ (nearly $70 \%$ of the $15 \mathrm{ppm}$ recommended by Bouis et al., 2011) in the polished rice grains, which is a significant increase as compared to many of the previously reported lines.

We recently reported that transformation of NFP rice (engineered for higher grain iron) with AtIRT1 could further increase the endosperm iron concentration by twofold, producing lines containing $9.67 \mu \mathrm{g} / \mathrm{g}$ DW iron in polished grains (Boonyaves et al., 2016). This encouraged us to engineer rice lines expressing AtIRT1, AtNAS1, and PvFERRITIN from a gene cassette present in the transgenic lines as a single locus. Many previous studies, including our own, have shown that single transgenic loci are robustly maintained over several generations. This approach minimizes the risk of transgenes segregating in consecutive generations. Importantly, iron levels in polished grains of the transgenic lines expressing AtIRT1, AtNAS1, and PvFERRITIN from a single cassette reported here are similar or higher than in NFP lines transformed with AtIRT1 (Boonyaves et al., 2016), suggesting that combining the three genes in a single locus has no negative consequences on their performance or significantly changes iron homeostasis in the plants. Furthermore, our results show that the concerted activity of IRT, NAS, and FERRITIN was superior for increasing endosperm iron content to combining IRT and FERRITIN only. Importantly, the transformed lines performed at par with the non-transformed cultivar in terms of several recorded growth parameters.

The expression of NAS increases NA and DMA production, which facilitates efficient uptake and long distance transport of iron (Hell and Stephan, 2003; Inoue et al., 2003; Takahashi et al., 2003; Kobayashi and Nishizawa, 2012). Chelators that facilitate translocation of iron are often also involved in uptake and transport of other metal ions. For example, in addition to iron, PS and NA transport other essential metal ions including zinc, manganese and copper (Haydon and Cobbett, 2007). Enzymes involved in PS biosynthesis are often upregulated under both iron, zinc, or copper deficiency conditions (Wintz et al., 2003; Suzuki et al., 2006). It is therefore not unexpected that expression of homologous or heterologous NAS genes in rice lines increases both iron and zinc content in the grains. In most of the rice plants engineered for higher endosperm iron, increases of iron were accompanied by moderate increases of zinc in the grains (Vasconcelos et al., 2003; Lee et al., 2009b; Masuda et al., 2009, 2012; Wirth et al., 2009; Johnson et al., 2011; Zhang et al., 2012; Tan et al., 2015; Trijatmiko et al., 2016), indicating that transgenic iron biofortification strategies have a positive effect on zinc levels. Expression of IRT1 in rice also increased zinc concentration in rice grains (Lee and An, 2009; Tan et al., 2015), which can be expected from the metal ion transport capacity of the IRT1

\section{REFERENCES}

Ahmad, H. R., Aziz, T., Hussain, S., Akraam, M., Sabir, M., Kashif, S. U. R., et al. (2012). Zinc-enriched farm yard manure improves grain yield and grain zinc concentration in rice grown on a saline-sodic soil. Int. J. Agric. Biol. 14, 787-792.

Aung, M. S., Masuda, H., Kobayashi, T., Nakanishi, H., Yamakawa, T., and Nishizawa, N. K. (2013). Iron biofortification of Myanmar rice. Front. Plant Sci 4:158. doi: $10.3389 /$ fpls.2013.00158 transporter (Korshunova et al., 1999). We found increases for zinc, copper, and manganese in polished grains of the transgenic rice lines expressing the AtIRT1, AtNAS1, and PvFERRITIN gene cassette, but increases in iron concentration were most significant. The greenhouse performance of the transgenic lines with regard to micronutrient biofortification and agronomic performance is a promising proof-of-concept that nutritionally sufficient iron levels in polished rice grains can be achieved. Field testing and breeding into consumer-preferred varieties is now necessary to demonstrate the agronomic robustness and nutritional benefit of the high-iron trait.

\section{AUTHOR CONTRIBUTIONS}

$\mathrm{NB}$ and WG conceived and designed the study, KB and T-YW carried out the experiments and analyzed the data, KB and NB wrote the manuscript, WG and NB edited the manuscript. All authors have read and approved the final manuscript.

\section{FUNDING}

We are grateful to Mrs. Jacqueline Imhof for her generous support of this work during KB's Ph.D. thesis research and acknowledge support from an ETH Research Grant to WG and NB.

\section{ACKNOWLEDGMENTS}

We thank Prof. Rainer Schulin (Soil Protection Group, ETH Zurich) for providing access to the ICP-OES facility and Björn Studer for his guidance in metal measurements. Seeds of rice cv. Nipponbare were kindly provided by Prof. Uta Paszkowski, University of Lausanne, Switzerland. We thank Irene Zurkirchen, Sebastian Oddsson, Salvatore Accardo, Rephael Iselin, and Pina Fritz for their help with the experimental work. We thank Prof. Dr. Mary Lou Guerinot and Aaron Atkinson for kindly providing the pIRT1 plasmid and Dr. Christof Sautter for providing the pMSB plasmid.

\section{SUPPLEMENTARY MATERIAL}

The Supplementary Material for this article can be found online at: http://journal.frontiersin.org/article/10.3389/fpls.2017.00130/ full\#supplementary-material

Bashir, K., Takahashi, R., Akhtar, S., Ishimaru, Y., Nakanishi, H., and Nishizawa, N. K. (2013). The knockdown of OsVIT2 and MIT affects iron localization in rice seed. Rice 6, 1-7. doi: 10.1186/1939-8433-6-31

Beard, J. L., and Connor, J. R. (2003). Iron status and neural functioning. Annu. Rev. Nutr. 23, 41-58. doi: 10.1146/annurev.nutr.23.020102. 075739

Boonyaves, K., Gruissem, W., and Bhullar, N. K. (2016). NOD promoter-controlled AtIRT1 expression functions synergistically with NAS and FERRITIN genes to 
increase iron in rice grains. Plant Mol. Biol. 90, 207-215. doi: 10.1007/s11103015-0404-0

Bouis, H. E., Hotz, C., McClafferty, B., Meenakshi, J. V., and Pfeiffer, W. H. (2011). Biofortification: a new tool to reduce micronutrient malnutrition. Food Nutr. Bull. 32, 31S-40S. doi: 10.1177/15648265110321S105

Cailliatte, R., Schikora, A., Briat, J. F., Mari, S., and Curie, C. (2010). Highaffinity manganese uptake by the metal transporter NRAMP1 is essential for Arabidopsis growth in low manganese conditions. Plant Cell 22, 904-917. doi: 10.1105/tpc.109.073023

Cakmak, I. (2008). Enrichment of cereal grains with zinc: agronomic or genetic biofortification? Plant Soil 302, 1-17. doi: 10.1007/s11104-007-9466-3

Cheng, L., Wang, F., Shou, H., Huang, F., Zheng, L., He, F., et al. (2007). Mutation in nicotianamine aminotransferase stimulated the $\mathrm{Fe}(\mathrm{II})$ acquisition system and led to iron accumulation in rice. Plant Physiol. 145, 1647-1657. doi: 10.1104/pp. 107.107912

Curie, C., Panaviene, Z., Loulergue, C., Dellaporta, S. L., Briat, J.-F., and Walker, E. L. (2001). Maize yellow stripel encodes a membrane protein directly involved in Fe(III) uptake. Nature 409, 346-349. doi: 10.1038/35053080

Eng, B., Guerinot, M., Eide, D., and Saier, M. Jr. (1998). Sequence analyses and phylogenetic characterization of the ZIP family of metal ion transport proteins. J. Membrane Biol. 166, 1-7. doi: 10.1007/s002329900442

Ford, G. C., Harrison, P. M., Rice, D. W., Smith, J. M., Treffry, A., White, J. L., et al. (1984). Ferritin: design and formation of an iron-storage molecule. Philos. Trans. R. Soc. B. 304, 551-565. doi: 10.1098/rstb.1984.0046

Glahn, R. P., Cheng, Z., Welch, R. M., and Gregorio, G. B. (2002). Comparison of iron bioavailability from 15 rice genotypes: studies using an in vitro digestion/Caco-2 cell culture model. J. Agric. Food Chem. 50, 3586-3591. doi: $10.1021 /$ jf0116496

Gomez-Galera, S., Sudhakar, D., Pelacho, A. M., Capell, T., and Christou, P. (2012). Constitutive expression of a barley Fe phytosiderophore transporter increases alkaline soil tolerance and results in iron partitioning between vegetative and storage tissues under stress. Plant Physiol. Biochem. 53, 46-53. doi: 10.1016/j. plaphy.2012.01.009

Goto, F., Yoshihara, T., Shigemoto, N., Toki, S., and Takaiwa, F. (1999). Iron fortification of rice seed by the soybean ferritin gene. Nat. Biotechnol. 17, 282-286. doi: 10.1038/7029

Gregorio, G. B., Senadhira, D., Htut, H., and Graham, R. D. (2000). Breeding for trace mineral density in rice. Food Nutr. Bull. 21, 382-386. doi: 10.1177/ 156482650002100407

Haydon, M. J., and Cobbett, C. S. (2007). Transporters of ligands for essential metal ions in plants. New Phytol. 174, 499-506. doi: 10.1111/j.1469-8137.2007.02051.x

Hell, R., and Stephan, U. W. (2003). Iron uptake, trafficking and homeostasis in plants. Planta 216, 541-551.

Hood, E., Gelvin, S., Melchers, L., and Hoekema, A. (1993). New Agrobacterium helper plasmids for gene transfer to plants. Transgenic Res. 2, 208-218. doi: 10.1007/BF01977351

Hurrell, R. (2002). Fortification: overcoming technical and practical barriers. J. Nutr. 132, 806S-812S.

Inoue, H., Higuchi, K., Takahashi, M., Nakanishi, H., Mori, S., and Nishizawa, N. K. (2003). Three rice nicotianamine synthase gene, OsNAS1, OsNAS2, and OsNAS3 are expressed in cells involved in long-distance transport of iron and differentially regulated by iron. Plant J. 36, 366-381. doi: 10.1046/j.1365-313X. 2003.01878.x

Inoue, H., Kobayashi, T., Nozoye, T., Takahashi, M., Kakei, Y., Suzuki, K., et al. (2009). Rice OsYSL15 is an iron-regulated iron(III)-deoxymugineic acid transporter expressed in the roots and is essential for iron uptake in early growth of the seedlings. J. Biol. Chem. 284, 3470-3479. doi: 10.1074/jbc.M806042200

Ishimaru, Y., Masuda, H., Bashir, K., Inoue, H., Tsukamoto, T., Takahashi, M., et al. (2010). Rice metal-nicotianamine transporter, OsYSL2, is required for the long-distance transport of iron and manganese. Plant J. 62, 379-390. doi: 10.1111/j.1365-313X.2010.04158.x

Ishimaru, Y., Suzuki, M., Tsukamoto, T., Suzuki, K., Nakazono, M., Kobayashi, T., et al. (2006). Rice plants take up iron as an Fe3+-phytosiderophore and as Fe2+. Plant J. 45, 335-346. doi: 10.1111/j.1365-313X.2005.02624.x

Johnson, A. A., Kyriacou, B., Callahan, D. L., Carruthers, L., Stangoulis, J., Lombi, E., et al. (2011). Constitutive overexpression of the OsNAS gene family reveals single-gene strategies for effective iron-and zinc-biofortification of rice endosperm. PLoS ONE 6:e24476. doi: 10.1371/journal.pone.0024476
Kobayashi, T., Nagasaka, S., Senoura, T., Itai, R. N., Nakanishi, H., and Nishizawa, N. K. (2013). Iron-binding haemerythrin RING ubiquitin ligases regulate plant iron responses and accumulation. Nat. Commun. 4, 2792. doi: 10.1038/ ncomms3792

Kobayashi, T., and Nishizawa, N. K. (2012). Iron uptake, translocation, and regulation in higher plants. Annu. Rev. Plant Biol. 63, 131-152. doi: 10.1146/ annurev-arplant-042811-105522

Kobayashi, T., Suzuki, M., Inoue, H., Itai, R. N., Takahashi, M., Nakanishi, H., et al. (2005). Expression of iron-acquisition-related genes in iron-deficient rice is coordinately induced by partially conserved iron-deficiency-responsive elements. J. Exp. Bot. 56, 1305-1316. doi: 10.1093/jxb/eri131

Korshunova, Y. O., Eide, D., Clark, W. G., Guerinot, M. L., and Pakrasi, H. B. (1999). The IRT1 protein from Arabidopsis thaliana is a metal transporter with a broad substrate range. Plant Mol. Biol. 40, 37-44. doi: 10.1023/A: 1026438615520

Kumpatla, S. P., and Hall, T. C. (1998). Recurrent onset of epigenetic silencing in rice harboring a multi-copy transgene. Plant J. 14, 129-135. doi: 10.1046/j.1365313X.1998.00097.x

Lee, S., and An, G. (2009). Over-expression of OsIRT1 leads to increased iron and zinc accumulations in rice. Plant Cell Environ. 32, 408-416. doi: 10.1111/j.13653040.2009.01935.x

Lee, S., Chiecko, J. C., Kim, S. A., Walker, E. L., Lee, Y., Guerinot, M. L., et al. (2009a). Disruption of OsYSL15 leads to iron inefficiency in rice plants. Plant Physiol. 150, 786-800. doi: 10.1104/pp.109.135418

Lee, S., Jeon, U. S., Lee, S. J., Kim, Y. K., Persson, D. P., Husted, S., et al. $(2009 b)$. Iron fortification of rice seeds through activation of the nicotianamine synthase gene. Proc. Natl. Acad. Sci. U.S.A. 106, 22014-22019. doi: 10.1073/ pnas.0910950106

Lee, S. C., Kim, Y., Jeon, U., Kim, Y., Schjoerring, J. K., An, G., et al. (2012). Activation of rice nicotianamine synthase 2 (OsNAS2) enhances iron availability for biofortification. Mol. Cells 33, 269-275. doi: 10.1007/s10059012-2231-3

Li, X., Chen, S., Lu, Z., Chang, T., Zeng, Q., and Zhu, Z. (2002). Impact of copy number on transgene expression in tobacco. Acta Bot. Sin. 44, $120-123$.

Lucca, P., Hurrell, R., and Potrykus, I. (2001). Genetic engineering approaches to improve the bioavailability and the level of iron in rice grains. Theor. Appl. Genet. 102, 392-397. doi: 10.1007/s001220051659

Masuda, H., Kobayashi, T., Ishimaru, Y., Takahashi, M., Aung, M. S., Nakanishi, H., et al. (2013). Iron-biofortification in rice by the introduction of three barley genes participated in mugineic acid biosynthesis with soybean ferritin gene. Front. Plant Sci. 4:132. doi: 10.3389/fpls.2013.00132

Masuda, H., Ishimaru, Y., Aung, M. S., Kobayashi, T., Kakei, Y., Takahashi, M., et al. (2012). Iron biofortification in rice by the introduction of multiple genes involved in iron nutrition. Sci. Rep. 2:543. doi: 10.1038/ srep00543

Masuda, H., Suzuki, M., Morikawa, K., Kobayashi, T., Nakanishi, H., Takahashi, M., et al. (2008). Increase in iron and zinc concentrations in rice grains via the introduction of barley genes involved in phytosiderophore synthesis. Rice 1, 100-108. doi: 10.1007/s12284-008-9007-6

Masuda, H., Usuda, K., Kobayashi, T., Ishimaru, Y., Kakei, Y., Takahashi, M., et al. (2009). Overexpression of the barley nicotianamine synthase gene HvNAS1 increases iron and zinc concentrations in rice grains. Rice 2, 155-166. doi: 10.1007/s12284-009-9031-1

Meng, F., Wei, Y., and Yang, X. (2005). Iron content and bioavailability in rice. J. Trace Elem. Med. Biol. 18, 333-338. doi: 10.1016/j.jtemb.2005. 02.008

Nishimura, A., Aichi, I., and Matsuoka, M. (2006). A protocol for Agrobacteriummediated transformation in rice. Nat. Protoc. 1, 2796-2802. doi: 10.1038/nprot. 2006.469

Ogo, Y., Itai, R. N., Kobayashi, T., Aung, M. S., Nakanishi, H., and Nishizawa, N. K. (2011). OsIRO2 is responsible for iron utilization in rice and improves growth and yield in calcareous soil. Plant Mol. Biol. 75, 593-605. doi: 10.1007/s11103011-9752-6

Oliva, N., Chadha-Mohanty, P., Poletti, S., Abrigo, E., Atienza, G., Torrizo, L., et al. (2014). Large-scale production and evaluation of marker-free indica rice IR64 expressing phytoferritin genes. Mol. Breed. 33, 23-37. doi: 10.1007/s11032-0139931-z 
Paul, S., Ali, N., Gayen, D., Datta, S. K., and Datta, K. (2012). Molecular breeding of OsFer 2 gene to increase iron nutrition in rice grain. GM Crops Food 3, 310-316. doi: $10.4161 /$ gmcr.22104

Phattarakul, N., Rerkasem, B., Li, L. J., Wu, L. H., Zou, C. Q., Ram, H., et al. (2012). Biofortification of rice grain with zinc through zinc fertilization in different countries. Plant Soil 361, 131-141. doi: 10.1007/s11104-012-1211-x

Prom-u-Thai, C., Dell, B., Thomson, G., and Rerkasem, B. (2003). Easy and rapid detection of iron in rice grain. Sci. Asia 29, 203-207. doi: 10.2306/ scienceasia1513-1874.2003.29.203

Qu le, Q., Yoshihara, T., Ooyama, A., Goto, F., and Takaiwa, F. (2005). Iron accumulation does not parallel the high expression level of ferritin in transgenic rice seeds. Planta 222, 225-233. doi: 10.1007/s00425-005-1530-8

Rajeevkumar, S., Anunanthini, P., and Sathishkumar, R. (2015). Epigenetic silencing in transgenic plants. Front. Plant Sci. 6:693. doi: 10.3389/fpls.2015. 00693

Sazawal, S., Black, R. E., Ramsan, M., Chwaya, H. M., Stoltzfus, R. J., Dutta, A., et al. (2006). Effects of routine prophylactic supplementation with iron and folic acid on admission to hospital and mortality in preschool children in a high malaria transmission setting: community-based, randomised, placebo-controlled trial. Lancet 367, 133-143. doi: 10.1016/S0140-6736(06)67962-2

Sharma, A. D., Gill, P. K., and Singh, P. (2003). RNA isolation from plant tissues rich in polysaccharides. Anal. Biochem. 314, 319-321. doi: 10.1016/S00032697(02)00689-9

Stoltzfus, R., Mullany, L., and Black, R. (2003). Iron Deficiency Anemia, Comparative Quantification of Health Risks: The Global Burden of Disease Due to 25 Selected Major Risk Factors. Cambridge: Harvard University Press.

Suzuki, M., Morikawa, K. C., Nakanishi, H., Takahashi, M., Saigusa, M., Mori, S., et al. (2008). Transgenic rice lines that include barley genes have increased tolerance to low iron availability in a calcareous paddy soil. Soil Sci. Plant Nutr. 54, 77-85. doi: 10.1111/j.1747-0765.2007.00205.x

Suzuki, M., Takahashi, M., Tsukamoto, T., Watanabe, S., Matsuhashi, S., Yazaki, J., et al. (2006). Biosynthesis and secretion of mugineic acid family phytosiderophores in zinc-deficient barley. Plant J. 48, 85-97. doi: 10.1111/j. 1365-313X.2006.02853.X

Takahashi, M., Terada, Y., Nakai, I., Nakanishi, H., Yoshimura, E., Mori, S., et al. (2003). Role of nicotianamine in the intracellular delivery of metals and plant reproductive development. Plant Cell 15, 1263-1280. doi: 10.1105/tpc.010256

Tan, S., Han, R., Li, P., Yang, G., Li, S., Zhang, P., et al. (2015). Over-expression of the MxIRT1 gene increases iron and zinc content in rice seeds. Transgenic Res. 24, 109-122. doi: 10.1007/s11248-014-9822-z

Tang, W., Newton, R. J., and Weidner, D. A. (2006). Genetic transformation and gene silencing mediated by multiple copies of a transgene in eastern white pine. J. Exp. Bot. 58, 545-554. doi: 10.1093/jxb/erl228
Terada, R., Ignacimuthu, S., Bauer, P., Kondorosi, E., Schultze, M., Kondorosi, A., et al. (2001). Expression of early nodulin promoter gene in transgenic rice. Curr. Sci. 81, 270-276.

Trijatmiko, K. R., Duenas, C., Tsakirpaloglou, N., Torrizo, L., Arines, F. M., Adeva, C., et al. (2016). Biofortified indica rice attains iron and zinc nutrition dietary targets in the field. Sci. Rep. 6, 19792. doi: 10.1038/srep19792

Vasconcelos, M., Datta, K., Oliva, N., Khalekuzzaman, M., Torrizo, L., Krishnan, S., et al. (2003). Enhanced iron and zinc accumulation in transgenic rice with the ferritin gene. Plant Sci. 164, 371-378. doi: 10.3389/fpls.2013.00158

WHO (2001). Iron Deficiency Anaemia: Assessment, Prevention and Control: A Guide for Programme Managers. Available at: http://apps.who.int/iris/ bitstream/10665/66914/1/WHO_NHD_01.3.pdf?ua=1

WHO (2015). The Global Prevalence of Anaemia in 2011. Available at: http://apps. who.int/iris/bitstream/10665/177094/1/9789241564960_eng.pdf?ua=1\&ua=1

WHO (2016). Iron Deficiency Anaemia. Available at: http://www.who.int/ nutrition/topics/ida/en/ [accessed August 29, 2016].

Wintz, H., Fox, T., Wu, Y. Y., Feng, V., Chen, W., Chang, H. S., et al. (2003). Expression profiles of Arabidopsis thaliana in mineral deficiencies reveal novel transporters involved in metal homeostasis. J. Biol. Chem. 278, 47644-47653. doi: 10.1074/jbc.M309338200

Wirth, J., Poletti, S., Aeschlimann, B., Yakandawala, N., Drosse, B., Osorio, S., et al. (2009). Rice endosperm iron biofortification by targeted and synergistic action of nicotianamine synthase and ferritin. Plant Biotechnol. J. 7, 631-644. doi: 10.1111/j.1467-7652.2009.00430.x

Xiong, H. C., Guo, X. T., Kobayashi, T., Kakei, Y., Nakanishi, H., Nozoye, T., et al. (2014). Expression of peanut Iron Regulated Transporter 1 in tobacco and rice plants confers improved iron nutrition. Plant Physiol. Biochem. 80, 83-89. doi: 10.1016/j.plaphy.2014.03.021

Zhang, Y., Xu, Y. H., Yi, H. Y., and Gong, J. M. (2012). Vacuolar membrane transporters OsVIT1 and OsVIT2 modulate iron translocation between flag leaves and seeds in rice. Plant J. 72, 400-410. doi: 10.1111/j.1365-313X.2012. 05088.x

Conflict of Interest Statement: The authors declare that the research was conducted in the absence of any commercial or financial relationships that could be construed as a potential conflict of interest.

Copyright (C) 2017 Boonyaves, Wu, Gruissem and Bhullar. This is an open-access article distributed under the terms of the Creative Commons Attribution License (CC BY). The use, distribution or reproduction in other forums is permitted, provided the original author(s) or licensor are credited and that the original publication in this journal is cited, in accordance with accepted academic practice. No use, distribution or reproduction is permitted which does not comply with these terms. 